\title{
Rapid monitoring of seagrass biomass using a simple linear modelling approach, in the field and from space
}

\author{
Mitchell Lyons ${ }^{1, *}$, Chris Roelfsema ${ }^{2}$, Eva Kovacs ${ }^{2}$, Jimena Samper-Villarreal ${ }^{3}$, \\ Megan Saunders ${ }^{3}$, Paul Maxwell ${ }^{4}$, Stuart Phinn ${ }^{2}$ \\ ${ }^{1}$ Centre for Ecosystem Science, School of Biological, Earth and Environmental Sciences, University of New South Wales, \\ Sydney 2052, Australia \\ ${ }^{2}$ Biophysical Remote Sensing Group, School of Geography, Planning and Environmental Management, \\ University of Queensland, Brisbane 4072, Australia \\ ${ }^{3}$ Marine Spatial Ecology Lab, School of Biological Sciences, University of Queensland, Brisbane 4072, Australia \\ ${ }^{4}$ School of Chemical Engineering, University of Queensland, Brisbane 4072, Australia
}

\begin{abstract}
Seagrass meadows are globally significant carbon sinks and increasingly threatened; and seagrass habitat provides critical ecosystem services, for which above-ground biomass is a key indicator. The capacity to quantify biomass in seagrass ecosystems is both critical and urgent, yet no methods exist to perform this at the large spatial scale required for management (e.g. regional/continental). We built linear model relationships between in situ above-ground biomass and seagrass percentage cover per seagrass species to estimate biomass from both point-based and landscape scale $\left(>100 \mathrm{~km}^{2}\right)$ seagrass data. First we used a set of linear models to estimate the biomass component of each seagrass species in over 20000 benthic photos. We then adapted this approach to estimate biomass from a time-series of remote sensing derived seagrass percentage cover and dominant species maps. We demonstrate accurate estimation of above-ground biomass using a set of methods that is not only more time and resource efficient than existing methods, but is sufficiently robust and generalisable for application at large spatial or temporal scales. Our method allows for quantification of above-ground biomass in seagrass ecosystems over spatial scales larger than can be tractably assessed using current site- and point-based measurement approaches, and at scales that are required to understand and manage seagrass systems to tackle anthropogenic climate change and other impacts.
\end{abstract}

KEY WORDS: Eelgrass $\cdot$ Satellite mapping $\cdot$ Remote sensing $\cdot$ Ground truth · Management - Halophila . Halodule $\cdot$ Zostera $\cdot$ Syringodium $\cdot$ Cymodocea

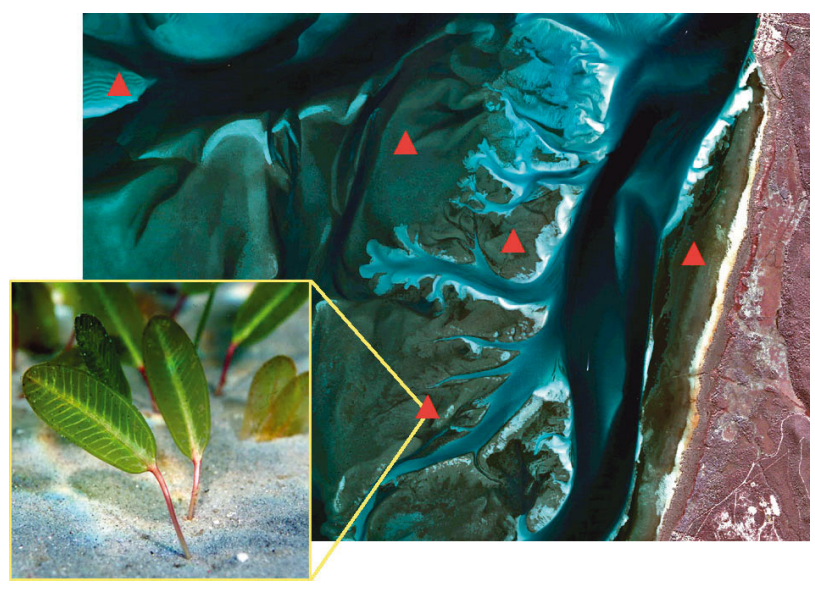

Using in situ measurements (red triangles), we modelled above-ground biomass in over 20000 benthic photos (inset) and a time-series of seagrass maps (main image).

Image: Digital Globe; Photo: Chris Roelfsema

\section{INTRODUCTION}

Seagrass habitats are economically and ecologically valuable coastal ecosystems. They are unfortunately facing many threats and are being lost at accelerating rates around the globe (Orth et al. 2006, Waycott et al. 2009). Seagrasses have significant capacity for carbon storage, and seagrass ecosystems are a globally significant carbon sink (Fourqurean et al. 2012); degradation of these habitats results in carbon re-emission (Pendleton et al. 2012). Seagrass habitats are highly productive and provide growing 
surfaces, stabilisation, and critical habitat at a range of trophic levels (Duarte \& Chiscano 1999). Increasing threats to seagrass ecosystems, and recent emphasis on the importance of carbon stocks in coastal ecosystems, or 'Blue Carbon' (Mcleod et al. 2011), has created an urgent need for broad scale, spatially explicit monitoring approaches to help develop and implement management programs (Duarte et al. 2013). A key indicator for these ecosystem services is above- and below-ground biomass. Seagrass monitoring techniques involve a wide range of spatial and temporal scales (Bortone 2000, Larkum \& Duarte 2006), from site $\left(\mathrm{m}^{2}\right)$ to regional $\left(\mathrm{km}^{2}\right)$ on a semiannual basis, but few studies have demonstrated techniques for monitoring of biomass over large areas with feasible repeat times or method reproducibility, whether by field sampling, modelling or mapping.

Traditional direct measures of seagrass biomass are destructive approaches that involve physically removing a sample or core of seagrass from the field, and subsequently analysing them in a laboratory. By nature this is expensive and time consuming. While field data collection provides accurate data and continues to be improved (e.g. Long et al. 1994), it is not adequate for repeatable monitoring over the size of areas that can be managed by governments or community groups. This has led to development of more rapid, non-destructive, visual assessment approaches (Mellors 1991, Mumby et al. 1997a, Kutser et al. 2007).

Mellors (1991) developed an approach where above-ground biomass was estimated visually in situ and ranked on a linear scale of 1 to 5, to one decimal place. Based on the lowest and highest biomass observed at the study site, a reference quadrat was established for each integer from 1 to 5 . These reference quadrats were then used as a guide to assign a biomass rank to multiple quadrats along transects across the study site. Biomass was harvested and measured for sets of reference quadrats, and a linear regression was used for calibration to biomass dry weight. Mumby et al. (1997a) built on this approach by increasing the ranking scale range to 1 to 6 and performing a more thorough calibration routine, providing analysis of sampling error/bias as well as sample size/statistical power relationships. Kutser et al. (2007) noted some possible limitations of these in situ visual assessment approaches, including prohibition/restrictions on destructive sampling in marine protected areas, but more importantly, time constraints in the context of fieldwork duration and observer training. They developed a photo-library approach that followed a similar methodology con- ceptually; however, instead of estimating biomass for each quadrat in situ, photos of the benthos were taken and the dry weight biomass for each photo was estimated post-fieldwork. This was achieved by comparing the photos to a reference photo library, created by harvesting and measuring a small number of quadrats across a range of above-ground biomass levels. This reduced the field time needed in comparison to the visual approach discussed above.

These 3 approaches all still require a visual estimate of biomass for every sample, and in situ estimation obviously cannot be used to estimate biomass retrospectively. Visual assessment of biomass also presents an inherent risk of being subjective and prone to human error, and calibration to particular study sites or sets of observers to mitigate these risks may reduce methodological transferability. Moreover, the physical and mental resources required are such that these techniques are unlikely to be feasible or repeatable over large areas (e.g. $>1000 \mathrm{~km}^{2}$, regional/continental) and replicable across observers. For some time, seagrass percentage cover and aboveground biomass measurements have been shown to be significantly correlated for numerous species (Heidelbaugh \& Nelson 1996). For the first component of this paper we demonstrate a simple, modelbased empirical approach for rapidly estimating species-specific above-ground biomass as a function of seagrass percentage cover from point-based seagrass composition data. We build biomass-cover models using a limited set of destructively sampled biomass cores, and estimate above-ground biomass, per species component, for a data set of over 20000 points. The point-based data set is derived from systematically acquired and analysed benthic photos over the period 2004-2013. Most notably, we demonstrate that this method is significantly more timeefficient per sample than published methods for in situ estimation, and requires significantly less field sampling effort.

The limited areal extent of traditional destructive biomass sampling and in situ estimation approaches $\left(<1 \mathrm{~km}^{2}\right)$ has led to the development of empirical remote sensing based mapping approaches (Armstrong 1993, Mumby et al. 1997b, Phinn et al. 2008, Knudby \& Nordlund 2011). These approaches generally build a relationship between above-ground biomass and the measured reflectance of seagrass from remotely sensed image data, and then apply the relationship to the full image data set. In clear waters, accuracy is relatively high in environments where seagrass meadows are dominated by one or 2 species (Armstrong 1993, Mumby et al. 1997b), but accuracy 
drops significantly in more complex environments comprising several different seagrass species and other benthic cover types (e.g. coral, macroalgae) (Phinn et al. 2008, Knudby \& Nordlund 2011). Even though biomass is correlated with percentage cover, when seagrass communities are comprised of morphologically different species, it follows that the remote sensing signal is more sensitive to a combination of canopy structure and percentage cover than biomass. For example, a ground level round leaf species (e.g. Halophila ovalis) is likely to have a lower biomass level than a taller long leaf species (e.g. Zostera muelleri) at an equivalent percentage cover level, even though they may exhibit a similar remote sensing signal in multi-spectral imagery. Although varying incident light angle/intensity and current direction can alter the remote sensing signal and therefore confound remote sensing percentage cover estimates, percentage cover is still a more reliable variable to map than biomass in complex seagrass environments (Phinn et al. 2008, Knudby \& Nordlund 2011), particularly at moderate resolution ( $\sim 30 \mathrm{~m}$ pixels) (Lyons et al. 2012).

For the second component of this paper we extend the utility of the model-based approach, to estimate above-ground biomass from spatially continuous, landscape scale $\left(>100 \mathrm{~km}^{2}\right)$ species and percentage cover data. We modify the species component approach and build dominant species biomass-cover models to estimate above-ground biomass from a nine-date time-series of species and percentage cover maps derived from high resolution satellite imagery (Roelfsema et al. 2014a). Combining this with the point-based estimates provides a time-series data set of seagrass biomass at a spatial and temporal scale not yet reported in published literature.

\section{MATERIALS AND METHODS}

\section{Study site}

The Eastern Banks is a series of shallow water banks $\left(\sim 200 \mathrm{~km}^{2}\right)$ covered by extensive seagrass meadows, located in the eastern side of Moreton Bay, Australia. It comprises 5 major seagrass habitat areas (Moreton Banks, Amity Banks, Chain Banks, Maroom Banks and Wanga Wallen Banks), which are surrounded by deep waters (Fig. 1). The Eastern Banks are well flushed by oceanic waters, meaning there is relatively little runoff from the city of Brisbane, which is $\sim 30 \mathrm{~km}$ to the west. The sub-tropical Eastern Banks support a range of inter- and sub-tidal environments, including seagrass, mangroves, saltmarshes, and sand and mud flats. The seagrass communities comprise 6 major species, including Halophila ovalis, $H$. spinulosa, Halodule uninervis, Zostera muelleri, Syringodium isoetifolium and Cymodocea serrulata. These species occur in a range of community types including monospecific stands, multispecific stands, as well as mixed communities with one or 2 dominant species. The majority of the seagrass beds occur in water depths of $<3 \mathrm{~m}$, although there are several patches of seagrass in waters 3 to $10 \mathrm{~m}$ deep, mostly $H$. spinulosa and $H$. ovalis.

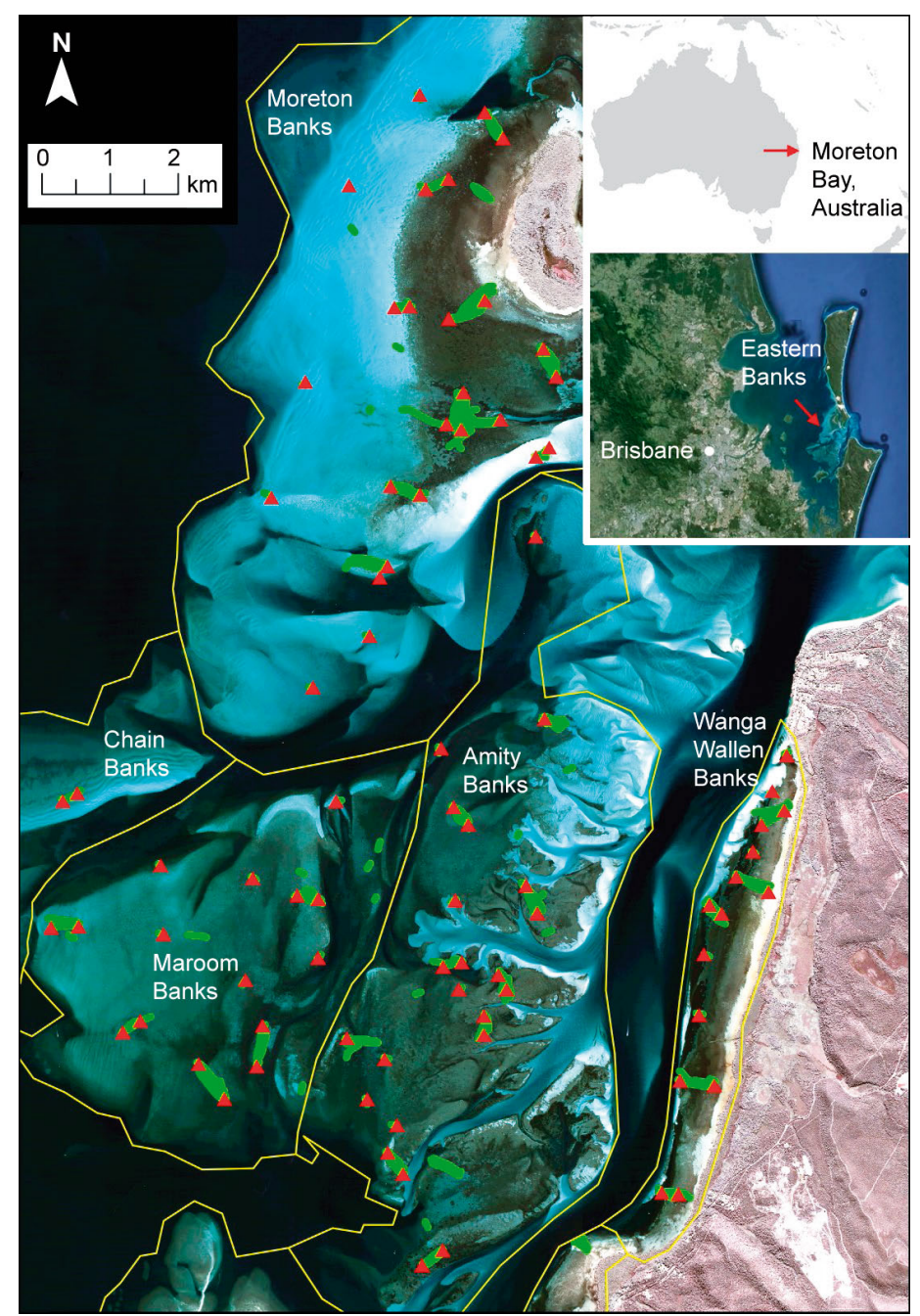

Fig. 1. Study site: geographical layout and extent of the Eastern Banks, Moreton Bay, Australia; approximate location and distribution of benthic photo transects from 2004-2013 (green lines) and biomass core locations from 2012-2013 (red triangles) 


\section{Model input data}

Biomass field data

Seagrass biomass cores were collected in 2012 and 2013 at 70 locations across the Eastern Banks, representing a range of species and biomass levels (core locations marked in Fig. 1). Biomass cores, $15 \mathrm{~cm}$ in diameter and $20 \mathrm{~cm}$ deep, were retrieved by a snorkeler or diver using a standard PVC pipe corer, and were taken at the beginning and end of snorkel photo transects to best ensure representation of the community types in the photos collected. Sediment was removed from the cores in situ using a $1 \mathrm{~mm}$ mesh bag, and remaining material was stored on ice, then frozen $\left(-20^{\circ} \mathrm{C}\right)$ until processed. Any detectable living organisms were returned to the ocean before cold storage. Epiphytes were removed both manually and with $10 \%$ hydrochloric acid, and then samples were dried at $60^{\circ} \mathrm{C}$. For each core, above and belowground biomass was measured for each species in grams dry weight (gDW). A coincident benthic photo was acquired before each core harvest; these photos were geo-referenced and analysed for seagrass percentage cover and species composition as per the method in the following section. Whilst above and below-ground biomass are reasonably well correlated, exploratory work suggested that predicting below-ground biomass from above-ground estimates would not be appropriate using the same simple linear modelling approach, which is expected given demonstrated variability in seagrass phenology in Moreton Bay (Maxwell et al. 2014). Thus we modelled above-ground biomass only, and all references to biomass refer to above-ground biomass. Biomass weight values were converted to a standard area unit $\left(\mathrm{gDW} \mathrm{m}^{-2}\right)$, which is the unit of measure implied when referring to biomass in this paper, unless explicitly stated otherwise.

\section{Point-based data: benthic photography}

Between 2004 and 2013 the Eastern Banks were repeatedly surveyed using a photo transect survey method (Roelfsema et al. 2009, 2014a), with a primary aim of calibrating and validating remote sensing mapping routines. A snorkeler towed a handheld GPS unit floating in a dry bag, capturing photos of the benthos $\sim 0.5 \mathrm{~m}$ above the substrate along a transect line, at $\sim 2 \mathrm{~m}$ intervals ( 1 $\mathrm{m}^{2}$ foot print). The snorkeler GPS log and photo time-stamp were synchronised in order to georeference each individual photo. Due to the logistics of working from boats and underwater, no absolute transect lines were followed, rather the start and end points of each transect were approximately matched for each survey campaign (transect spatial distribution can be seen in Fig. 1). Each photo was analysed for seagrass percentage cover and species composition using a 24 point grid in Coral Point Count Excel as described by Roelfsema et al. (2014a). Seagrass percentage cover is defined as the amount of substrate covered by seagrass from a birds-eye-view (referred to simply as seagrass cover). Depending on seagrass species composition, presence of other benthic cover types (e.g. coral, macroalgae) and substrate type, the average analysis rate was 75 photos $\mathrm{h}^{-1}$. Between 2004 and 2013 around 20000 photos were collected and analysed (see Table S1 in the Supplement at www.int-res.com/articles/suppl/m530p001_supp.pdf) and are freely available on PANGAEA (Roelfsema et al. 2015).

Landscape scale data: seagrass maps

We loosely define landscape scale as being both a large area $\left(>100 \mathrm{~km}^{2}\right)$ and spatially continuous. The landscape-scale seagrass data used for modelling are seagrass species and cover maps for 9 dates from 2004 to 2013, covering a seagrass area of around $150 \mathrm{~km}^{2}$. Seagrass species and cover map products used in this paper are presented elsewhere (Roelfsema et al. 2014a), and are freely available on PANGAEA (Roelfsema et al. 2014b). High resolution satellite images (Quickbird-2 and Worldview-2) were acquired coincident to the photo transect data described above, and used to map seagrass cover and seagrass species. Seagrass cover was mapped using discrete cover classes, with each class representing a $10 \%$ interval (i.e. $1-10 \%, 11-20 \%$, etc.), and seagrass species was mapped as either a single dominant species or alternatively as mixed seagrass. Contiguous patches of the same cover or species class are simply referred to as 'polygons'. Overall accuracy (Congalton \& Green 2009) ranged from 48 to $58 \%$ (mean: $52 \%$ ) for the cover maps, and 68 to $80 \%$ (mean: $77 \%$ ) for the species maps.

\section{Biomass modelling}

Percentage cover

We explored the relationship between seagrass biomass and seagrass percentage cover by fitting a range 
of model types and comparing both their fit and predictive power. Using data from 70 biomass cores and coincident benthic photos, we fit a standard least squares regression between total above-ground biomass and photo estimated percentage cover (single linear term), with both raw and log transformed biomass values. We refer to this model as the 'mixed species' model. We then re-fit this least squares regression with a second and third order polynomial term. Mumby et al. (1997a) suggest transformation of the biomass values to satisfy parametric regression assumptions, and we chose to implement a natural log transformation. Log transformed biomass provided lower prediction error and marginally less pattern in residual plots; thus from this point, all references to biomass modelling imply log transformed values, unless otherwise stated.

To further explore the relationship between biomass and cover, and increase the understanding of predictive power, we also modelled the data using a generalised linear model (GLM) and a generalised additive model (GAM). These models allow specification of an error distribution family; thus no log transformation of the response was required. We used a gamma distribution (with inverse link function) due to biomass values being strictly non-negative.

Seagrass species vary in structural and morphological characteristics, meaning that at a similar percentage cover level, the amount of biomass contained within an area is unlikely to be the same between species. In this study, we demonstrate biomass estimation stratified by seagrass species type, similar to allometric and component techniques used for estimating biomass for terrestrial vegetation (Jenkins et al. 2003). Firstly, we estimated individual species biomass at the point-based sample scale using a benthic photo data set - we refer to this as the 'species component model'. We then adapted this method to estimate biomass at the landscape scale using remote sensing derived seagrass maps of cover and dominant species we refer to this model as the 'dominant species model'. Here we demonstrate these stratified approaches using least squares regression, though the exact methodology could be repeated for any model type (see Results section justifying selection of least squares over a GLM/GAM).

\section{Point-based data}

A least squares regression was used to model above-ground biomass as a function of photo estimated percentage cover (single linear term), sepa- rately for each species component. The component models were then used to predict the above-ground biomass component (AGBC) for each species, with the estimated combined above-ground biomass (AGB) being the sum of the components:

$$
\mathrm{AGB}=\sum_{i=S_{1}}^{S_{n}} \mathrm{AGBC}_{i}
$$

where $S_{1 \ldots n}$ represents each species of seagrass. This component model was then used to estimate biomass at locations and time periods where biomass cores were not sampled, which comprised $\sim 20000$ photos collected between 2004 and 2013. This method can be applied to any photograph that can be analysed for species composition, or in fact any point-based measurement of species composition and cover.

\section{Landscape scale}

The component method requires full species composition information, meaning it cannot be applied to the seagrass map products, as each polygon in the map only has one percentage cover and one dominant species label. Therefore the method was simplified to accept only one cover and species value as model input. The biomass core data was stratified into subsets based on dominant species, and a least squares regression was then fitted separately to each subset. Dominant was defined as that species comprising $>55 \%$ of the total biomass. Though we found no effect, readers can easily regenerate models and statistics using a higher threshold specified at the beginning of the modelling code. AGB can then be predicted conditionally as the corresponding dominant species estimate $\left(\mathrm{AGB}_{\mathrm{Spp}}\right)$ or where there was no dominant species, from the mixed species model $\left(\mathrm{AGB}_{\text {mix }}\right)$ :

$$
\mathrm{AGB}=\left\{\begin{array}{l}
\mathrm{AGB}_{\mathrm{Spp}_{n},} \text { if species } 1 \ldots n \text { is dominant } \\
\mathrm{AGB}_{\text {mix }}, \text { otherwise }
\end{array}\right.
$$

This dominant species model was then used to estimate biomass from the seagrass cover and species map products, where the model was applied to each polygon in the seagrass map. This was achieved by applying the appropriate model coefficients to each map using a simple Python 2.7 script in ArcGIS 10.1. Since the seagrass cover maps were in $10 \%$ interval categories, the mid-point of each class was used as the predictor variable. If it were more suitable for the application, a biomass estimate range could be computed using the upper and lower limits of the cover category. It is also worth mentioning here that this 
method can be applied to seagrass maps derived from either passive (i.e. satellite multispectral) or active (i.e. acoustic/SONAR) mapping approaches, so the methods are not limited to systems that are either shallow or have optically clear water. In fact, these methods can be applied to a map derived from any approach (e.g. hand drawn, manual interpretation of aerial photography/Google Earth imagery, modelled layers).

Model fitting and uncertainty

To provide estimates of uncertainty and the expected prediction error in larger data sets, models were evaluated with overall root mean square error (RMSE), $k$-fold cross validation prediction error and repeated $k$-fold cross validation prediction error. Overall RMSE was calculated from the prediction residuals on the final model fits for all available data. $k$-fold prediction error was calculated as the mean error (RMSE) of prediction into the test folds of a $k$-fold cross validation. Repeated $k$-fold prediction error is the same metric, except the mean is calculated from multiple random iterations of the $k$-fold cross validation, which can serve to reduce the variance in error estimates (Rodríguez et al. 2010). We performed $k$ fold cross validation with $k=1, \ldots, 10$, to determine possible effects of $k$ on error estimate bias (Rodríguez et al. 2010). These values will display Monte Carlo variation due to assignment of different random splits, though this is greatly reduced in the repeated $k$-fold metric. We chose cross validation over bootstrap methods for estimating prediction error due to the possibility that bootstrap methods may result in bias when predicting into very large data sets (e.g. 20000 photos) (Kim 2009). We take these error estimates as an error range for the final biomass products; a 95\% interval could be taken on the repeated $k$-fold cross validation, though Vanwinckelen \& Blockeel (2012) caution that such use may be inappropriate. We also produced modelled versus observed biomass plots for visual assessment of the mixed species, species component and dominant species modelling approaches.

We also analysed the effect of sample size on model performance, as this significantly affects the cost-benefit consideration for the field sampling effort required. Fitting seagrass cover and biomass from the full data set (i.e. the mixed species model), we simulated a sample size of $n=2,3, \ldots, 70$, and recorded the least squares coefficients, $\mathrm{R}^{2}$ and RMSE. We ran this simulation 10000 times and calculated a 95\% interval for both bootstrap and permutation resampling.

\section{Data accessibility}

All modelling and calculations were performed using the open source language R (R Core Development Team 2013). All code and data required to reproduce results is available as a Supplement (www.int-res. com/articles/suppl/m530p001_supp.zip) and continued improvements will be available at: http://bitbucket.org/ mitchest/lyons_biomassmodelling/.

\section{RESULTS}

\section{Model performance}

Seventy biomass cores and coincident analysed field photos were used to develop the biomass estimation models. Data exploration showed that Zostera muelleri and Halodule uninervis were not being reliably discriminated (in both the photo and remote sensing analysis) due to their morphological similarity, and as such they were treated as a single species complex for this study. Based on many years of field data collection (Roelfsema et al. 2013) and studies in the area, we know that $Z$. muelleri is the dominant species and thus suspect it will most likely be the correct identification.

Fit and error statistics modelling total biomass and total cover are shown in Table 1. As mentioned above, log transformed biomass provided a lower prediction error and marginally less patterned residuals and was therefore chosen as the preferred response variable for the modelling in this study. Addition of second and third order polynomial terms or use of a GLM/GAM did not noticeably affect fit statistics and were thus not further explored in this study. Varying $k$ in the $k$-fold cross validation routines did not have a significant impact on error margins (see Table S2 in the Supplement at www.int-res.com/articles/suppl/m530p001_ supp.pdf), thus we opted for the standard 10-fold cross validation for all routines. The consistency of biomass prediction error around 24 to $26 \mathrm{gDW} \mathrm{m}^{-2}$ demonstrates a stable and robust relationship between biomass and percentage cover, and could serve as a baseline error margin for estimates.

Fit and error statistics for the species component modelling approach are shown in Table 2, and for the dominant species modelling approach in Table 3. These results again demonstrate a strong relationship between biomass and percentage cover, with the species component regression models showing marginally better fits. However, Cymodocea serrulata has a significantly larger error margin in both 
cases, probably due to generally only being found at higher biomass levels. The opposite is the case for Halophila ovalis. The consistency between overall RMSE, and $k$-fold and repeated $k$-fold prediction error suggests the models should generalise well to new larger data sets. The prediction errors for each species can be taken as the expected error margin for the corresponding species estimates in the final biomass products.

To evaluate predictive performance of the final biomass products, we generated standard modelled versus observed plots for the species component and dominant species model, as well as the mixed species regression fit (Fig. 2). These plots also include an error margin calculated for different biomass ranges to better inform users of uncertainty at different biomass levels. The species component and dominant species models resulted in a marked improvement in estimation compared to the mixed species linear model, which is evident visually and in the improved RMSE values. This provides the core motivation for utilisation of the methods demonstrated here.
Sample size simulation showed that there was negligible variation in model performance for around $n>$ 40 samples, higher but likely acceptable variation for $25<\mathrm{n}<40$ sample, and unacceptable variance for about $\mathrm{n}<25$ samples (Fig. 3 and see Fig. S1 in the Supplement). Minimum sample size is likely to vary with species composition, as well as with environmental or physiological variation within the study area. Thus it is difficult to make an absolute recommendation on minimum sample size.

\section{Biomass estimations}

\section{Point-based data}

The species component biomass model was used to estimate biomass from around 20000 points with cover and species composition derived from benthic photos between 2004 and 2013. For each photo, the model gives an estimate of above-ground biomass for each species present. Fig. 4 shows a graphical sum-
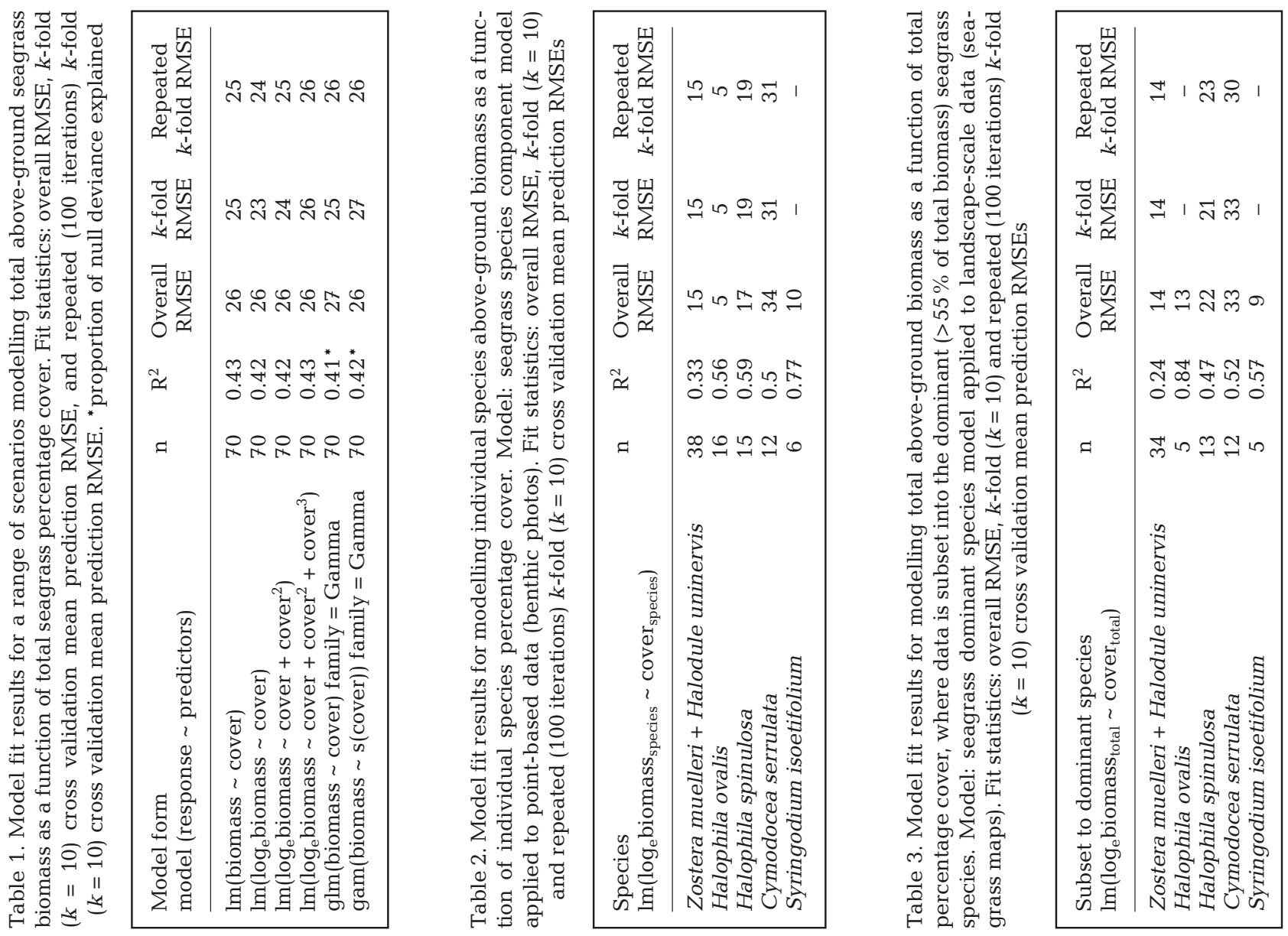

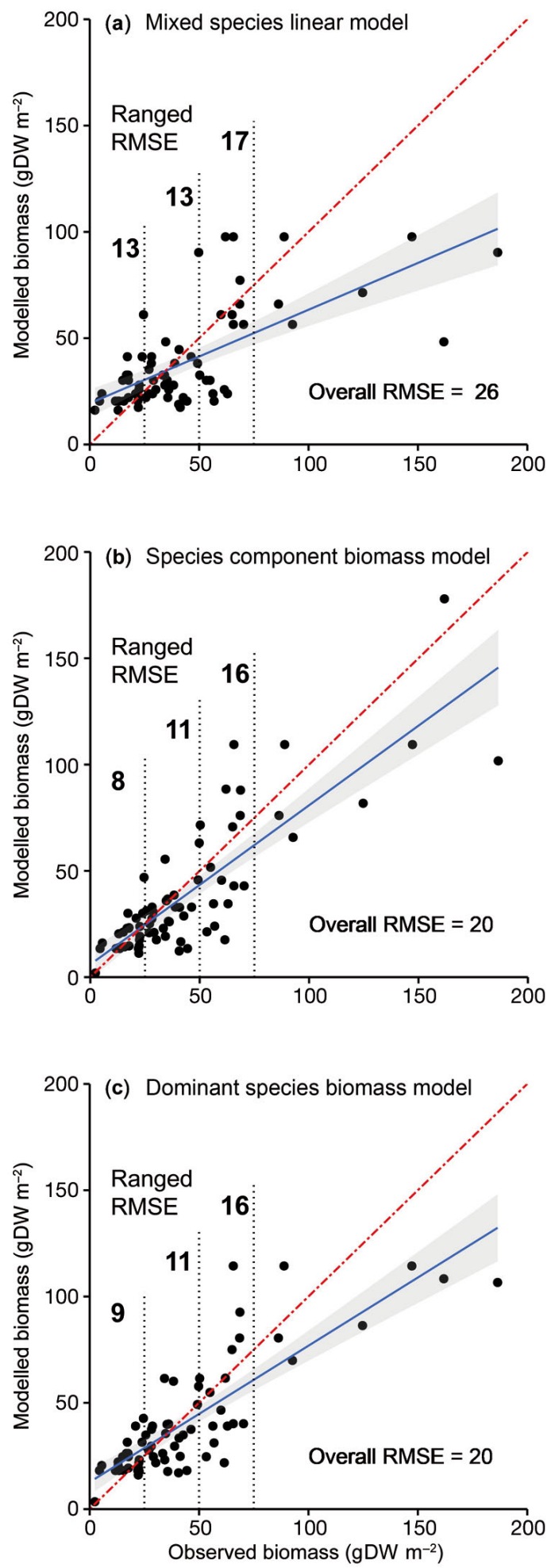

Fig. 2. Observed vs. model predicted seagrass aboveground biomass for (a) mixed species linear regression, (b) species component biomass model and (c) dominant species biomass model. Lines: linear fit (blue) and 1-to-1 (red). RMSE values (in bio-mass gDW $\mathrm{m}^{-2}$ ): overall RMSE and ranged RMSE for observed biomass values $<25,<50$, and $<75$ (dotted line) mary of biomass estimates using the full June 2012 photo data set as an example (other years can be produced using the data/code supplied), demonstrating the level of detail that can be obtained from a data set in each year.

\section{Landscape scale}

The dominant species biomass model was used to estimate biomass from 9 seagrass cover/species map sets between 2004 and 2013. The model gives an estimate of total above-ground biomass for every polygon in the seagrass map, thus creating a spatially continuous biomass map. By multiplying the estimated biomass value $\left(\mathrm{gDW} \mathrm{m} \mathrm{m}^{-2}\right)$ by the area $\left(\mathrm{m}^{2}\right)$ of each seagrass map polygon, estimates of total aboveground biomass weight (gDW or kgDW) were also calculated. Fig. 5 shows the June 2012 biomass map as an example (other years can be produced using the data/code supplied) and a time-series plot of total DW biomass on the Wanga Wallen Banks calculated from the biomass maps from 2004 to 2013.

\section{Application of autotrophic thresholds}

Duarte et al. (2010) provide some empirically derived thresholds of above-ground biomass, at which various seagrass species and meadows tend to be

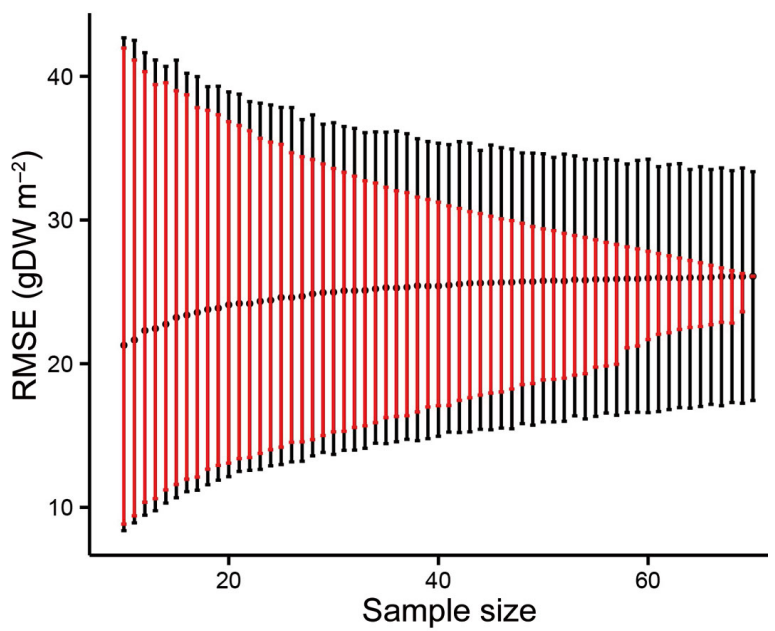

Fig. 3. Effect of sample size on RMSE between seagrass percentage cover and seagrass above-ground biomass, simulated from a random sample of size $n=2,3, \ldots, 70$. Simulation was run 10000 times; Statistics: permutation resampling mean $(\bullet)$ and $95 \%$ intervals for bootstrap (black bars) and permutation (red bars) resampling. See Fig. S1 in the Supplement (www.int-res.com/articles/suppl/m530p001_supp.pdf) for similar plots produced for $\mathrm{R}^{2}$ and coefficients 

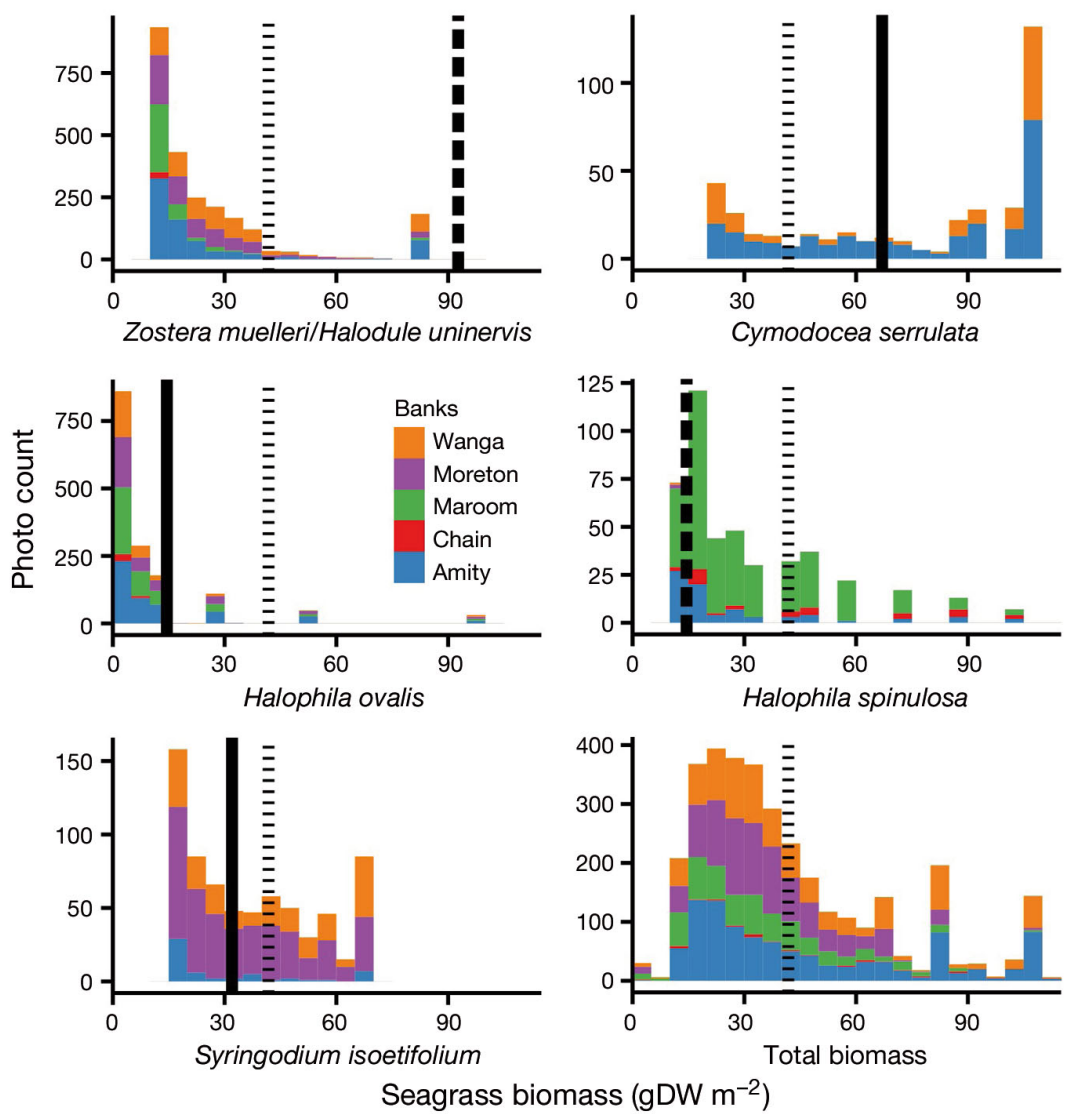

Fig. 4. Seagrass above-ground biomass estimates from the species component biomass model for June 2012 benthic photo data from the Eastern Banks, Moreton Bay, Australia. Occurrence frequency of photos across the biomass range is for each species and total biomass (bottom right plot). Note varying range on $y$-axis. Colours: different seagrass habitat areas (Banks) within the study area. Vertical lines = autotrophic thresholds $\left(A_{t}\right)$ as defined by Duarte et al. (2010): species specific $A_{t}$ (solid line), closely related species $A_{\mathrm{t}}$ (thick dotted line), mixed species $A_{\mathrm{t}}$ (thin dotted line). See Table 2 for expected error margins on biomass predictions for each species

autotrophic and act as $\mathrm{CO}_{2}$ sinks. Although these thresholds are likely to vary across environmental and geographical gradients, we demonstrate this as a potential tool for simultaneous assessment of the carbon budget by incorporating these thresholds into the results (Figs. $4 \& 5$ ).

\section{DISCUSSION}

\section{Model performance}

The biomass modelling in this study builds on established knowledge of the relationship between percentage cover and above-ground biomass (Heidelbaugh \& Nelson 1996), and demonstrates the critical role of species composition when modelling biomass as a function of percentage cover. We show how confounding factors in using percentage cover (such as species morphology, or prevailing light condition/ current that changes apparent percentage cover; Mumby et al. 1997a), may in part be reconciled by incorporating species composition into modelling. Accordingly, we observed a reduction in the error margin of biomass prediction when going from a single linear model of percentage cover versus total biomass to the species component or dominant species ensembles (Fig. 2). From visual assessment and the RMSE values at difference biomass ranges (Fig. 2), the mixed species and dominant species models tend to underestimate at higher biomass levels, which is marginally resolved in the species component model. Underestimation results from higher error margins on estimation of Cymodocea serrulata, which makes up most of the samples with biomass $>75 \mathrm{gDW}$ $\mathrm{m}^{-2}$. The high error margin and underestimation is a consequence of canopy height. At high percentage cover levels, C. serrulata grows at a range of canopy heights, thus several patches at the same percentage cover level can have significantly different biomass. Other species in the study area tend not to have this property. Interestingly, in Mumby et al. (1997a), estimate variation also increased at higher biomass levels. The species component model also has marginally better error margins at lower biomass ranges. We expect this effect is likely to increase with increasing species heterogeneity due to the species component model better accounting for morphological differences between species, though we could not explicitly test this since most of the samples used in this study had a clear dominant species $(\sim 75 \%$ of samples were $>75 \%$ comprised of 1 species).

\section{Uncertainty in biomass estimates}

In context of the model fitting and application to the point-based photo data set, the main source of uncertainty is the assumption made about the simplicity of the relationship between biomass and cover. Seagrass in Moreton Bay displays high phenotypic plasticity (Maxwell et al. 2014), with morpho- 


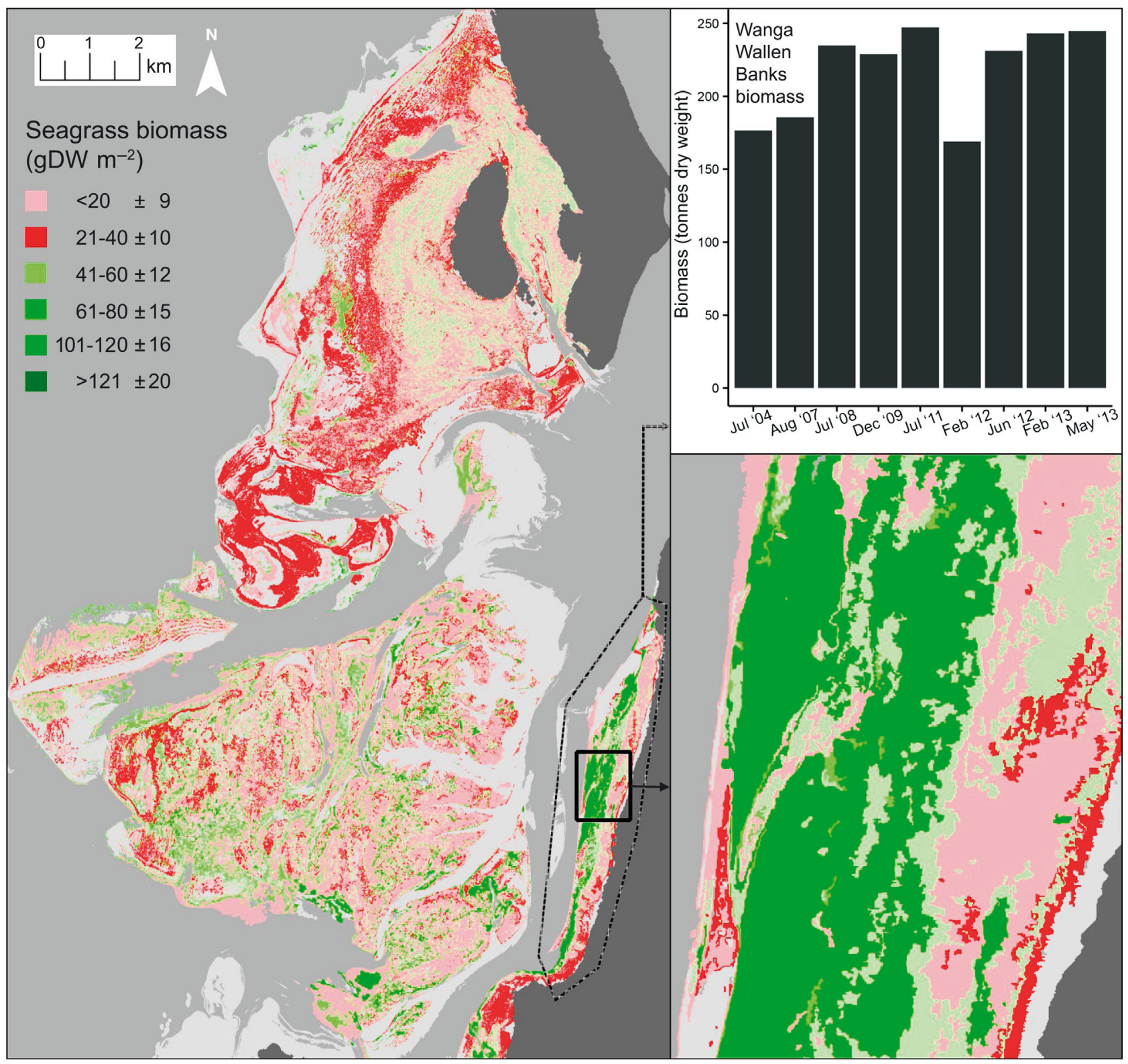

Fig. 5. Biomass map for June 2012 on the Eastern Banks, Moreton Bay, Australia, generated by applying the dominant species biomass model to seagrass percentage cover and dominant species maps. Map inset: zoomed in view of the Wanga Wallen Banks. Bar plot: total dry weight (DW) of biomass (tonnes) over time on the Wanga Wallen Banks (defined by dotted line), calculated by applying the dominant species biomass model to the full time-series of seagrass maps. Colour scheme $=$ net autotrophic threshold for mixed species seagrass $\left(A_{\mathrm{t}}\right)$ as defined by Duarte et al. (2010): $<A_{\mathrm{t}}(\mathrm{reds})$, $>A_{\mathrm{t}}$ (greens). See Table 3 for expected error margins in biomass predictions

logy varying markedly with changing water properties and depth. This is particularly the case for Zostera muelleri, which is the dominant species in this study. This would reduce the strength of a linear relationship between percentage cover and biomass within a particular species. For example the $Z$. muelleri/Halodule uninervis complex had a lower $\mathrm{R}^{2}$, though in this case the prediction error margin was not anomalously higher than other species. Another factor to consider is the effect of canopy structure on the biomass-cover relationship. For example, Halophila ovalis has round oval shaped leaves that lie parallel to the substrate, which increases the percentage cover value disproportionately to biomass compared to the other species which have (usually longer) leaves that grow vertically. It is worth noting that a 
similar effect may also occur at very low tide or under strong water current, where a usually vertical canopy may align at an angle to or flat on the substrate. We suggest that both morphological variation within species and canopy structure could be accounted for with further model stratification or increased degrees of freedom (e.g. additional terms or environmental covariate predictors as in Carr et al. 2012).

Measurement error is also a common source of uncertainty. We expect that at the point-based spatial scale, measurement error is negligible in this study since the biomass samples were analysed by experienced biologists, and the photos were analysed by experienced photo analysts who have worked in the study area for over a decade. The spatial scale of the biomass core data $\left(<1 \mathrm{~m}^{2}\right)$ is not appropriate to assess biomass estimates at the seagrass mapping unit spatial scale ( $>5$ to $10 \mathrm{~m}^{2}$ ). Without biomass field data at this scale (it is unlikely this type of data is even obtainable), we make the assumption that the model fit and cross validation statistics scale up from photos to polygons. That is, the uncertainty component in the biomass map products due to the modelling is defined by the regression fit and cross validated prediction error margins. In practice, upon applying the dominant species model to the seagrass maps, error in the seagrass maps propagates through to the resultant biomass maps. The overall accuracy of both the cover and species maps theoretically define the maximum accuracy for the biomass map. The accuracy of the resultant biomass map is then a function of the propagated error from each map plus the biomass model error. The accuracy of the maps also affects the uncertainty in biomass estimation in different ways.

Error in the species map will result in using the wrong set of coefficients for biomass prediction; thus the propagated map error will depend on the difference from the coefficients of the true species. In our case, species were mapped relatively accurately (mean: $~ 80 \%$ ), so we would expect to apply the wrong set of coefficients to only $20 \%$ of the map polygons. As an example, consider a $Z$. meulleri polygon with $30 \%$ cover: predicting biomass with the Cymodocea serrulata or Syringodium isoetifolium coefficients would result in a prediction error of +13 or $+8 \mathrm{gDW} \mathrm{m}^{-2}$, respectively. Error in the cover map will result in using the wrong cover value in predicting biomass, thus the propagated map error will depend on the magnitude of the cover map error and the steepness of the slope coefficient. In our case, we expect this to be a more common source of error since the cover maps have a lower mean overall accuracy $(\sim 50 \%)$. However, since the cover map cat- egories are ordinal, we can calculate a fuzzy accuracy measure: if a discrepancy of $\pm 10 \%$ cover is added, the mean overall accuracy for the cover maps is much higher $(\sim 75 \%)$. So we would expect that only $25 \%$ of the map polygons would have a significant biomass estimation error. As an example, again consider a $Z$. meulleri polygon with a true cover of $30 \%$ : a mapping error of $\pm 10 \%$ would result in a biomass prediction error of around $\pm 3 \mathrm{gDW} \mathrm{m}^{-2}$, whereas a mapping error of $+50 \%$ would result in an error of around $+23 \mathrm{gDW} \mathrm{m}{ }^{-2}$. If it were feasible to collect a sufficient number of map polygon scale biomass measurements, it would be possible to more accurately estimate the error components discussed above.

\section{Advantages of model-based biomass estimation}

We have introduced a range of biomass monitoring approaches in this paper, and here we will outline some advantages of our model-based approach, the foremost being time-efficiency. The method described here is significantly more time efficient than both destructive core sampling and in situ visual methods over the spatial scales demonstrated in this study. For example, disregarding biomass core analysis, using in situ estimation by an observer, Mumby et al. (1997a) state an analysis time of 37.5 site estimates per hour (which at the time was a significant improvement in sampling efficiency), in contrast to 65.2 site estimates $\mathrm{h}^{-1}$ for our method, equating to a $\sim 74 \%$ increase in time efficiency. This is given a mean photo acquisition rate of 500 photos $\mathrm{h}^{-1}$ in situ, and a mean photo analysis rate of 75 photos $\mathrm{h}^{-1}$ post field. Note that for producing the model estimations there is no practical time difference in processing with respect to site number. For example, running our R code on 70 biomass cores and the 3549 photos from the year 2012 registers an elapsed time of $<2 \mathrm{~s}$. Excitingly, there is significant research into automated analysis of composition of benthic photos (Beijbom et al. 2012), which would not only improve composition analysis, but the biomass estimation would be practically instantaneous, decreasing the overall analysis time by orders of magnitude.

Besides overall time, our approach also offers 2 more potential resource savings. Firstly, the majority of processing time is post-field, which will equate to significant resource savings in terms of field work time and cost. Secondly, the analysed photos were not only used for biomass modelling, but were also used to calibrate the seagrass cover and species mapping routines from Roelfsema et al. (2014a). These 2 
savings could be a significant factor when analysing cost benefit for field planning.

Explicitly comparing the visual and our modelbased approach, one might expect that a visual interpretation method would provide a more accurate estimate of biomass, though data from other studies do not support this. Estimate variation between observers shown in Kutser et al. (2007) is not significantly different to prediction error margins for estimates in this study. Similarly, variation of sample means and the error range for overlapping biomass categories in Mumby et al. (1997a) were also not significantly different to prediction error margins for estimates in this study. In fact, being able to provide an estimate of prediction error that applies consistently across 1000 s of estimates is one of the key advantages of a model-based approach. Compared to visual assessment, an advantage of a model-based approach is that estimates are not subjective and are less prone to human error (both absolute error and variance between observers). Though one could argue that observer bias is simply replaced with model error, model error is repeatable and easier to quantify. Another unique advantage of the species component model approach on point-based data is that biomass is estimated per species. None of the published methods offer a feasible approach for estimating biomass separately for each occurring species.

We expect that our approach will be more robust when transferring to other data sets and environments, the only requirement being that a stable model relationship can be developed between biomass and seagrass predictor variables. Compared to quantifying observer bias and variability in visual assessment methods, model performance and prediction error is more easily and consistently identified over very large areas and very large sample numbers. We also expect that our approach will be robust generalising to different predictor data structures. Biomass can be estimated when only seagrass cover data (point- or map-based) is available, useful for scenarios where species information has not or cannot be derived. For example, multi-temporal seagrass mapping that extends back before high-resolution satellite imagery was available is unlikely to yield species information at all (Lyons et al. 2013). A key property of the methods in this study is that biomass can be estimated retrospectively, which cannot be done with in situ visual approaches. Future improvements in spectral unmixing and inversion methods (e.g. Dekker et al. 2011) may yield high resolution species composition data at landscape scale $\left(>100 \mathrm{~km}^{2}\right)$, allowing application of the full species component approach. Finally, and purely speculatively, it may be possible to adapt these methods to other biota such as macroalgae or corals.

\section{Future work and final remarks}

A key aspect of future work would be to build a library of biomass field data for more seagrass species and for specific growing seasons. Duarte \& Chiscano (1999) as well as Hossain et al. (2010) demonstrated significant temporal variability in biomass, thus it would be prudent to explicitly test the effect of seasonality on the biomass-cover relationship. This would be a step towards a more automated monitoring approach, enabling biomass estimation in new study sites without the need for in situ sampling. Future work should also aim to increase model complexity and introduce environmental covariate data to reconcile the non-linear relationship with changing species morphology, as discussed above; the data sets already exist in Moreton Bay (Saunders et al. 2013, Maxwell et al. 2014).

Seagrass ecosystems comprise one of the most important carbon sinks on earth and assessment of the carbon stocks in these systems is an important component of carbon accounting projects (e.g. Blue Carbon initiatives). This study has demonstrated a simple and robust methodology for estimating seagrass above-ground biomass over large spatial areas based on benthic photos, satellite image derived maps, and limited in situ field sampling. We note that whilst above-ground biomass is a key indicator, belowground biomass can be the major component of storage. The relationship between above- and belowground biomass has been demonstrated for some time (Duarte \& Chiscano 1999); thus we hope that modelling of this relationship will utilise results from the methodology demonstrated here to also predict below-ground biomass at similarly large scales. Reviving analogies to terrestrial vegetation, more efficient and accurate estimation of structural (e.g. biomass) and physiological (e.g. light use) properties began with work similar to that in this paper. For example using simple aggregated 'big leaf' models, analogous to aggregating seagrass species, is less accurate than using models developed to incorporate different structural and floristic forms (Nightingale et al. 2004). The methods we describe in this paper could therefore be an important tool for accurately quantifying the carbon in seagrass ecosystems over spatial scales larger than can be tractably assessed using traditional in situ measurement approaches. 
Acknowledgements. Funding was provided by University of Queensland, CSIRO, Coastal Zone CRC, ARC Linkage (J. Marshall and S.P.), UWA-UQ BRCA (K. van Neil and S.P.). Fieldwork was carried out by Seagrass Watch, Moreton Bay Research Station, Rodney Borrego, Kate Obrien, Ian Leiper, Robert Canto, Nadia Aurisch, Robin Aurisch, Novi Adi, Peran Bray, Russ Babcock and Matt Dunbabin. WorldView2 Imagery was provided by Digital Globe.

\section{LITERATURE CITED}

Armstrong RA (1993) Remote-sensing of submerged vegetation canopies for biomass estimation. Int J Remote Sens 14:621-627

Beijbom O, Edmunds PJ, Kline DI, Mitchell BG, Kriegman D (2012) Automated annotation of coral reef survey images. In: Computer Vision and Pattern Recognition (CVPR), 2012 IEEE Conf, 16-21 Jun 2012, Providence, RI. Curren Associates, Red Hook, NY, p 1170-1177

Bortone SA (2000) Seagrasses: monitoring, ecology, physiology, and management. CRC Press, Boca Raton, FL

> Carr JA, D'Odorico P, McGlathery KJ, Wiberg PL (2012) Stability and resilience of seagrass meadows to seasonal and interannual dynamics and environmental stress. J Geophys Res 117:G01007, doi:10.1029/2011JG001744

Congalton R, Green K (2009) Assessing the accuracy of remotely sensed data: principles and practices, 2nd edn. Taylor \& Francis, London

> Dekker AG, Phinn SR, Anstee J, Bissett P and others (2011) Intercomparison of shallow water bathymetry, hydrooptics, and benthos mapping techniques in Australian and Caribbean coastal environments. Limnol Oceanogr Methods 9:396-425

> Duarte CM, Chiscano CL (1999) Seagrass biomass and production: a reassessment. Aquat Bot 65:159-174

> Duarte CM, Marba N, Gacia E, Fourqurean JW, Beggins J, Barron C, Apostolaki ET (2010) Seagrass community metabolism: assessing the carbon sink capacity of seagrass meadows. Global Biogeochem Cycles 24:GB4026, doi:10.1029/2010GB003848

> Duarte CM, Kennedy H, Marba N, Hendriks I (2013) Assessing the capacity of seagrass meadows for carbon burial: current limitations and future strategies. Ocean Coast Manage 83:32-38

> Fourqurean JW, Duarte CM, Kennedy H, Marba N and others (2012) Seagrass ecosystems as a globally significant carbon stock. Nat Geosci 5:505-509

Heidelbaugh WS, Nelson WG (1996) A power analysis of methods for assessment of change in seagrass cover. Aquat Bot 53:227-233

Hossain M, Rogers K, Saintilan N (2010) Variation in seagrass biomass estimates in low and high density settings: implications for the selection of sample size. Environ Ind $5: 17-27$

Jenkins JC, Chojnacky DC, Heath LS, Birdsey RA (2003) National-scale biomass estimators for United States tree species. For Sci 49:12-35

Kim JH (2009) Estimating classification error rate: repeated cross-validation, repeated hold-out and bootstrap. Comput Stat Data Anal 53:3735-3745

Knudby A, Nordlund L (2011) Remote sensing of seagrasses in a patchy multi-species environment. Int J Remote Sens 32:2227-2244

Kutser T, Vahtmae E, Roelfsema CM, Metsamaa L (2007)
Photo-library method for mapping seagrass biomass. Estuar Coast Shelf Sci 75:559-563

Larkum AWD, Orth RJ, Duarte CM (2006) Seagrasses: biology, ecology, and conservation. Springer, Dordrecht

> Long BG, Skewes TD, Poiner IR (1994) An efficient method for estimating seagrass biomass. Aquat Bot 47:277-291

> Lyons MB, Phinn SR, Roelfsema CM (2012) Long term land cover and seagrass mapping using Landsat and objectbased image analysis from 1972 to 2010 in the coastal environment of South East Queensland, Australia. ISPRS J Photogramm Remote Sens 71:34-46

> Lyons MB, Roelfsema CM, Phinn SR (2013) Towards understanding temporal and spatial dynamics of seagrass landscapes using time-series remote sensing. Estuar Coast Shelf Sci 120:42-53

Maxwell PS, Pitt KA, Burfeind DD, Olds AD, Babcock RC, Connolly RM (2014) Phenotypic plasticity promotes persistence following severe events: physiological and morphological responses of seagrass to flooding. J Ecol 102: $54-64$

Mcleod E, Chmura GL, Bouillon S, Salm R and others (2011) A blueprint for blue carbon: toward an improved understanding of the role of vegetated coastal habitats in sequestering $\mathrm{CO}_{2}$. Front Ecol Environ 9:552-560

- Mellors JE (1991) an evaluation of a rapid visual technique for estimating seagrass biomass. Aquat Bot 42:67-73

- Mumby PJ, Edwards AJ, Green EP, Anderson CW, Ellis AC, Clark CD (1997a) A visual assessment technique for estimating seagrass standing crop. Aquatic Conserv Mar Freshw Ecosyst 7:239-251

Mumby PJ, Green EP, Edwards AJ, Clark CD (1997b) Measurement of seagrass standing crop using satellite and digital airborne remote sensing. Mar Ecol Prog Ser 159: 51-60

Nightingale JM, Phinn SR, Held AA (2004) Ecosystem process models at multiple scales for mapping tropical forest productivity. Prog Phys Geogr 28:241-281

> Orth RJ, Carruthers TJB, Dennison WC, Duarte CM and others (2006) A global crisis for seagrass ecosystems. Bioscience 56:987-996

> Pendleton L, Donato DC, Murray BC, Crooks S and others (2012) Estimating global 'blue carbon' emissions from conversion and degradation of vegetated coastal ecosystems. PLoS ONE 7:e43542

> Phinn SR, Roelfsema CM, Dekker AG, Brando V, Anstee J (2008) Mapping seagrass species, cover and biomass in shallow waters: an assessment of satellite multi-spectral and airborne hyper-spectral imaging systems in Moreton Bay (Australia). Remote Sens Environ 112:3413-3425

R Core Development Team (2013) R: a language and environment for statistical computing. R Foundation for Statistical Computing, Vienna. www.r-project.org

> Rodríguez JD, Perez A, Lozano JA (2010) Sensitivity analysis of kappa-fold cross validation in prediction error estimation. IEEE Trans Pattern Anal Mach Intell 32:569-575

Roelfsema CM, Phinn SR, Udy N, Maxwell P (2009) An integrated field and remote sensing approach for mapping seagrass cover, Moreton Bay, Australia. J Spatial Sci 54: 45-62

Roelfsema C, Kovacs EM, Saunders MI, Phinn S, Lyons M, Maxwell P (2013) Challenges of remote sensing for quantifying changes in large complex seagrass environments. Estuar Coast Shelf Sci 133:161-171

> Roelfsema C, Lyons M, Kovacs E, Maxwell P, Saunders M, Samper-Villarreal J, Phinn S (2014a) Multi-temporal 
mapping of seagrass cover, species and biomass: a semiautomated object based image analysis approach. Remote Sens Environ 150:172-187

Roelfsema CM, Lyons MB, Kovacs EM, Maxwell P, Saunders MI, Samper-Villarreal J, Phinn SR (2014b) Multitemporal mapping of seagrass cover, species and biomass of the Eastern Banks, Moreton Bay, Australia, with links to shapefiles. PANGAEA, available at http://doi. pangaea.de/10.1594/PANGAEA.833767

Roelfsema CM, Kovacs EM, Lyons MB, Phinn SR (2015) Benthic and substrate cover data derived from a time series of photo-transect surveys for the Eastern Banks, Moreton Bay Australia, 2004-2014. PANGAEA, available at http://doi.pangaea.de/10.1594/PANGAEA.846147

Editorial responsibility: Just Cebrian,

Dauphin Island, Alabama, USA
Saunders MI, Leon J, Phinn SR, Callaghan DP and others (2013) Coastal retreat and improved water quality mitigate losses of seagrass from sea level rise. Glob Change Biol 19:2569-2583

Vanwinckelen G, Blockeel H (2012) On estimating model accuracy with repeated cross-validation. In: De Baets B, Manderick B, Rademaker M, Waegeman W (eds) Proc 21st Belgian-Dutch Conf Machine Learning, Ghent, Ghent University, p 39-44. Available at www.benelearn2012. ugent.be/proceedings/BeneLearn2012_Procedings.pdf

Waycott M, Duarte CM, Carruthers TJB, Orth RJ and others (2009) Accelerating loss of seagrasses across the globe threatens coastal ecosystems. Proc Natl Acad Sci USA 106:12377-12381

Submitted: October 24, 2014; Accepted: April 21, 2015 Proofs received from author(s): June 10, 2015 